\title{
Perfect Restorative Diagnosis: Myth or Reality?
}

\author{
Prasanna B Dhatavkar ${ }^{1} \odot$, Shalini D Aggarwal ${ }^{2} \odot$, Rhea S Digholkar ${ }^{3} \odot$, Neil V Lewis ${ }^{4} \odot$, Poorva S Kurtarkar ${ }^{5} \oplus$, Piyush Oswal ${ }^{6} \odot$
}

\begin{abstract}
Aim and objective: To summarize the basic and advanced diagnostic aids that are able to diagnose dental caries at both the nascent and the advanced stages.

Background: Shift in the proportion of mineral loss and gain results in tooth caries, which is considered to be pathological. Tooth decay is a continuous process from a physiological to pathological one and is influenced by many variables. Thus, there is a lack of definite limit among healthy and diseased, owing to the subjective nature of the tooth loss and its potential to remineralize.

Review results: In dental practice, the most commonly used tool is the traditional intraoral periapical (IOPA) radiograph that remains the standard for most of the clinician. But most clinicians are likely to use additional approaches for the detection of lesions, given the two-dimensional (2D) nature of the IOPA radiographs and the 3D invasiveness of dental caries. The objective of this view is to explore a well-rounded approach to diagnosis dental caries to eliminate as many surprises as possible while performing a restorative treatment.

Conclusion: A diligent and methodical approach leads to the elimination of confounders and enables the clinician to arrive at a comprehensive diagnosis.
\end{abstract}

Keywords: Dental caries, Diagnosis, Radiograph.

Journal of Operative Dentistry and Endodontics (2021): 10.5005/jp-journals-10047-0104

\section{BACKGROUND}

Restorations are necessary in order to replace diseased or defective tooth structures and reestablish their appearance, function, and integrity. The basic concepts in restoring defects of teeth must be clearly understood by dental professionals so that a durable and functional restoration can be provided. ${ }^{1,2}$

Preoperative assessment, dental radiographs, and other diagnostic aids are important in restorative therapy to determine the extent of caries and existing tooth morphology. It is equally important to determine the reason for dental decay and provide a cumulativeappraisal of the tooth involved. Atsubsequentfollow-ups, based on these radiographs, the tooth restorability and ramification of intervention may be assessed. Intraoral periapical (IOPA) radiograph, although a great source of information, has a severe limitation in the fact that it is a two-dimensional (2D) image of 3D structures. The reading of this $2 \mathrm{D}$ image is very subjective and may vary from clinician to clinician, depending upon the clinician's experience and acumen. A mesiodistal width of the caries and its coronogingival depth are the facts easily available on the 2D image; however, the buccolingual width of the carious lesion remains elusive. Preassessment of the case at hand allows the clinician to anticipate the treatment plan and discuss this with the patient, thereby disallowing any future negative discussions. ${ }^{3}$

This review attempts to create a ready reckoner for clinicians to avoid missteps in diagnosis.

\section{Review Result}

Commonly used traditional approaches when combined with more sensitive methods may amend caries diagnosis and also will help clinicians in practicing restorative dentistry more apt to the type of lesion. ${ }^{2}$

\section{Discussion}

There are a few commonly overlooked concerns, which when not addressed will lead to cascading errors later. A few of these missteps
${ }^{1-6}$ Department of Conservative Dentistry and Endodontics, Dr DY Patil Dental College and Hospital, Dr DY Patil Vidyapeeth, Pune, Maharashtra, India

Corresponding Author: Shalini D Aggarwal, Department of Conservative Dentistry and Endodontics, Dr DY Patil Dental College and Hospital, Dr DY Patil Vidyapeeth, Pune, Maharashtra, India, Phone: +91 9890820006, e-mail: shalini1972minia@gmail.com

How to cite this article: Dhatavkar PB, Aggarwal SD, Digholkar RS, et al. Perfect Restorative Diagnosis: Myth or Reality? J Oper Dent Endod 2021;6(1):11-13.

Source of support: Nil

Conflict of interest: None

are discussed at length, some are obvious and others are easy to miss. Information has been gathered to create a ready reckoner for diagnostic aids and their effective use.

\section{Failure to Detect Tooth Fracture/Cracks}

Often radiographs are not assessed properly to diagnose root fractures or cracks, which are often seen as a J-shaped radiolucency. This radiolucency is detected over a period of time and is a surrogate symptom of the actual fracture. The early detection of cracks is unlikely and often escapes detection on a 2D radiograph if there is no symptom set. Cone-beam computed tomography evaluation of such incomplete suspected fractures will often elicit an unambiguous image. ${ }^{4}$

\section{Failure to Detect Caries}

Caries at a microscopic level is a loss of calcium ions from the hydroxyapatite crystals and up to a certain stage will be reversible if detected. When the incipient mineral loss goes undetected, cavitated caries occurs, which is then to be restored, or use of remineralizing agent can be done. Detection of these noncavitated 
lesions should have high sensitivity and specificity. DIAGNOdent is a useful clinical adjunct to identify these caries. It works on the principle that sound teeth emit different wavelengths from carious tooth structure. Based on the wavelengths emitted, the machines gives a single reading in a scale of $0-99$, based on the premise that higher readings are indicative of higher decay. ${ }^{5}$

\section{Occlusal Load Assessment}

Balanced occlusion is a key factor for the prevention of muscular pain related to masticatory muscles. The chances of noncarious cervical lesions occurring in the cases of perfectly balanced occlusion are almost nonexistent. In order for prevention and quantitative assessment of balance occlusal load, dental prescale system is a device used for the examination of a balanced occlusion. This device uses a testing sheet that undergoes a chemical reaction by color developing, for detecting contact areas and a computerized analysis system. Prescale systems had limitations and problems faced were for the safety to be used in the oral cavity because of its color developing points which was obvious during the assessment. ${ }^{6}$

\section{Assessment for Masticatory Functions}

The gnathodynamometer is an old method used for the study of the function of mastication. They give information about the strength of muscle of mastication, periodical reactivity, and physiological and functional balance of teeth present. This instrument measures the data obtained by the masticatory muscles during elevation and depression of the mandible. ${ }^{6}$

The studies obtained by techniques of Gnathodynamometer are of objective methods for quantitative assessment of masticatory apparatus. Thus, this equipment demands specialized instrument, are costly and time-consuming. ${ }^{6}$

Reassurance that the occlusal load is being properly distributed with no outliers is of utmost importance to a restorative dentist. The absence of uniformity of load distribution, combined with a failure of the dentist to rectify this disparity could well cause damage to the healthy tooth tissue and cause a failure of the restoration that has been executed. ${ }^{6}$

\section{Why Preoperative Assessment is Necessary and Its Future Implications}

The detection and diagnosis of dental caries aim to prevent the progress of surface demineralization of the organic and inorganic matrices to cavitation. The aforementioned methods and techniques alone are not adequate for diagnosis of tooth decay. Judicious use of all pertinent knowledge, available to a clinician, combined with basic, and state of the art technology, could definitely eliminate the iatrogenic errors that would arise from incomplete and casual information gathering (Table 1). ${ }^{3,7}$

\section{Clinical Significance}

All the mentioned caries diagnosis and detection techniques have some limitations, thereby are subjected to errors with less than

Table 1: Methods used in diagnosis of tooth decay

\begin{tabular}{|c|c|}
\hline Visual inspection & $\begin{array}{l}\text { Alteration in the structure of tooth such as dissolution of enamel, discoloration, white spot lesion, presence } \\
\text { of cavitation, surface roughness can be assessed in the visual examination. When illuminated under suitable } \\
\text { light, the caries structure makes light and enamel look opaque and white. This is because of } \\
\text { demineralization due to an increase in porosity. }\end{array}$ \\
\hline Caries detecting dyes & $\begin{array}{l}\text { Caries detection dyes tend to stain less mineralized organic matrix but do not stain bacteria which has been } \\
\text { concluded by most clinical investigations. In a study, Demarco et al. proposed that the remnant of dye which } \\
\text { was remaining on cavity walls can stimulate reduction in shear bond strength among enamel and composites. }\end{array}$ \\
\hline Fiber-optic transillumination & $\begin{array}{l}\text { During the examination of the less mineralized or carious tissue with fiber-optic device, dark shadow is } \\
\text { observed due to low light transmission index over dentinal tubules compared to sound tooth structure. The } \\
\text { best use of fiber-optic transillumination device is for detecting proximal lesions and depth of occlusal lesions. }\end{array}$ \\
\hline $\begin{array}{l}\text { Digital imaging: fiber-optic } \\
\text { transillumination }\end{array}$ & $\begin{array}{l}\text { The device is the compound of fiber-optic transillumination and a digital camera, so as to lower the limitations } \\
\text { of fiber-optic transillumination. As per the studies conducted, this method is noninvasive as it does not use } \\
\text { ionizing radiation that is harmful and comparatively more sensitive than X-rays in detecting early } \\
\text { demineralization of tooth. This digital imaging is useful in detecting fluorosis and fracture in the tooth. }\end{array}$ \\
\hline Xeroradiography & $\begin{array}{l}\text { Xeroradiography is much more sensitive as compared to D-speed films. Edge enhancement is offered by } \\
\text { this method. Margins or edges are well distinguishable in the areas of different densities. It was considered a } \\
\text { reliable method for many years for the detection of caries but previous studies have suggested that it is good } \\
\text { as E-speed films used in dental radiographs. }\end{array}$ \\
\hline Subtraction radiography & $\begin{array}{l}\text { The method is commonly used in the assessment of tooth decay and loss of bone in periodontology. Digital } \\
\text { assessment is done by taking picture of the required radiograph with a video camera of high-quality } \\
\text { resolution. Later the picture is shifted to a computer imaging software device named digitizer. Same amount } \\
\text { of required beam is superimposed on two standardized radiographs using software. Thus, the two images } \\
\text { appear dark bright in appearance. }\end{array}$ \\
\hline Fluorescence & $\begin{array}{l}\text { Based on the fluorescence method, two methods have been developed of the organic component of teeth, one } \\
\text { of which is DIAGNOdent that uses infrared light which has a wavelength of } 655 \mathrm{~nm} \text { wavelength and } \\
\text { another one is quantitative light-induced fluorescence with a wavelength of } 290-450 \mathrm{~nm} \text { which uses an arc lamp. }\end{array}$ \\
\hline $\begin{array}{l}\text { Quantitative light-induced } \\
\text { fluorescence }\end{array}$ & $\begin{array}{l}\text { Is a method which uses a principal that has the content of tooth mineral which changes the autofluorescence. } \\
\text { The scattering of light changes faster in carious tissues as compared to normal mineralized tissue by } \\
\text { decreasing the absorption and lowering the pathway of light in the lesions and fluorescence in the area. This } \\
\text { states that the scattering of light is used for the assessment of loss of inorganic and organic contents related } \\
\text { to tooth decay. The range of red fluorescence can be assessed for plaques on dentures, oral hygiene, infected } \\
\text { dentin, and defective leakage of sealants. }\end{array}$ \\
\hline
\end{tabular}


Cone-beam computed tomography

Infrared fluorescence

Mini-D

DIAGNOdent

Ultrasonics (ultrasound caries detector)
Cone-beam computed tomography is widely used in orthodontic treatment planning, implants placement, grafting procedure, assessment of the temporomandibular joint, examination of trauma patients, and detection of caries.

A wavelength of $700-15000 \mathrm{~nm}$ is used for irradiation of tooth and the resulting fluorescence is measured by using barrier filter. In a study by Longbottom, he mentioned that this method was able to differentiate among carious and sound enamel and dentin. Further future reports are needed for efficacy in future implication.

It is easy to use and does not require calibration. It is based on fiber-optic principle. Proximal and occlusal caries is detected by its LED and fiber-optic technology. This device emits a wavelength of 635-880 nm, analyzes the reflected light tooth surface, and is converted to electric signals. Light and sound are two signals used for identification of the presence of caries (green light turns red).

The method has a parametric value of 0-99. The healthiest state of tooth is indicated by the value 0 . This technique is useful in diagnosing initial lesion without tooth cavity. On different surface of tooth, different decalcification values can be measured. The wavelength of $655 \mathrm{~nm}$ is emitted by a fiber-optic probe directed onto occlusal surface of tooth.

The caries is detected with the help of sound wave used. The device can detect lesions early because the travel time of the pulse of ultrasonics differs in sound and demineralized enamel tissue. As the white spot lesion has adhered to enamel, it does not tend to produce any noticeable or weal sound reflection whereas higher amplitudes are produced by deeper lesions, which makes the method promising in detecting early enamel lesions. perfect reliability. The assessment of tooth decay should focus on sound surfaces, instead of detecting lesions biased toward operative approach. False-positive approach is more likely in terms of an unnecessary treatment approach. Thus, clinicians are more convergent on the detection of lesion than on sound surface, particularly to avoid commanding deep lesions. It is at this moment; practitioner uses additional diagnostic tool to complete the decision of when to interpose. . $^{3,7}$

\section{CONCLUSION}

For caries assessment and planning of treatment, additional caries diagnosis and detection techniques and methods should be used supplementary for clinical decision-making in conjunction with caries risk assessment. For premature restorative intervention, none of the mentioned methods should be used.

\section{ACKnOWLedgment}

The authors and corresponding authors did not receive any funding from any institution.

\section{ORCID}

Prasanna B Dhatavkar (1) https://orcid.org/0000-0001-6115-4482 Shalini D Aggarwal 으 https://orcid.org/0000-0001-9522-6560 Rhea S Digholkar () https://orcid.org/0000-0003-4248-3189
Neil V Lewis @ https://orcid.org/0000-0002-8038-1063

Poorva S Kurtarkar 이 https://orcid.org/0000-0002-1842-9548

Piyush Oswal @ https://orcid.org/0000-0002-0223-4295

\section{References}

1. Srilatha A, Doshi D, Kulkarni S, et al. Advanced diagnostic aids in dental caries - a review. J Global Oral Health 2019;2(2):118-127. DOI: 10.25259/JGOH_61_2019.

2. Shivakumar AT, Kalgeri SH, Dhir S. Clinical considerations in restorative dentistry - a narrative review. J Int Clin Dent Res Organ 2015;7(2):122129. DOI: $10.4103 / 2231-0754.164377$.

3. Gomez J. Detection and diagnosis of the early caries lesion. BMC Oral Health 2015;15(Suppl. 1):S3. DOI: 10.1186/1472-6831-15-S1-S3.

4. Khasnis SA, Kidiyoor KH, Patil AB, et al. Vertical root fractures and their management. J Conserv Dent 2014;17(2):103-110. DOI: 10.4103/09720707.128034 .

5. Khalife MA, Boynton JR, Dennison JB, et al. In vivo evaluation of DIAGNOdent for the quantification of occlusal dental caries. Oper Dent 2009;34(2):136-141. DOI: 10.2341/08-54.

6. Konstantinova D, Dimova M. Historical review of gnathodynamometric methods used for the assessment of masticatory function. J IMAB 2016;22(2):1226-1229. DOI: 10.5272/ jimab.2016223.1226.

7. Hülya Y, Sultan K. Recent methods for diagnosis of dental caries in dentistry. Meandros Med Dent J 2018;19:1-8. DOI: 10.4274/meandros.21931.

8. Abogazalah N, Ando M. Alternative methods to visual and radiographic examinations for approximal caries detection. J Oral Sci 2017;59(3):315-322. DOI: 10.2334/josnusd.16-0595. 